\title{
希薄高分子水溶液の微小管路内流れに関する研究*
}

\author{
渡 辺敬三*1, 平尾 宗 彦*2, 小方 聡*3
}

\section{Flow Characteristics of Dilute Polymer Solutions in a Micro Tube}

\author{
Keizo WATANABE*4, Munehiko HIRAO and Satoshi OGATA \\ *4 Tokyo University of Agriculture and Technology, Department of Technology and Risk Management, \\ 2-24-16 Naka-cho, Koganei-shi, Tokyo, 184-8588 Japan
}

\begin{abstract}
Pressure drop and velocity profile for a micro tube were investigated on laminar flow of distilled water and dilute polymer solutions. It is the range of $50.2-251.8 \mu \mathrm{m}$ in diameter, and the value of $1 / \mathrm{d}$ is about 340 . By a pressure drop measurement it is shown that the experimental data agree with Hagen-Poiseuille equation in the case of Newtonian fluids. And the flow rate of the dilute polymer solutions increased comparing with that of distilled water at the low Reynolds number range. The increase ratio of the flow rate is about $15 \%$ in maximum in the case of $d=251.8 \mu \mathrm{m}$. For the result of micro PIV measurement, there are few differences between the velocity profile of distilled water and Peo 5 ppm solution.
\end{abstract}

Key Words: Dilute Polymer Solution, Circular Pipe, Laminar Flow, Micro Tube, Micro PIV, Pressure Drop

\section{1. 緒}

高分子水溶液の微小管内層流における流れがニュー トン流体とは異なることが実験的に明らかにされてい る.すなわち, 高分子水溶液の微小管内流れにおける 流量は, 円すい一平板粘度計により得られた粘性挙動 を基に算出される流量より大きな増加を示す(1).この 流量増加は見掛けの滑りに起因すると考えられ, 壁近 傍における高分子の希薄な層の形成によるものである という仮定が一般的になされている.この層内の粘度 がバルク粘度に比べ低いため滑りなし条件に反するこ となく管内を流動する流体が滑りを起こしているよう に見えるというものである．高分子水溶液のこの滑り 速度は壁面ずり応力とともに増加するが, shear thinningによる粘度低下が顕著なため全流量に対する滑

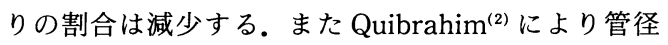
の減少に伴い見掛けの粘度が減少し, 臨界直径よりも

* 原稿受付 2005 年 4 月 1 日.

*1 正員, 東京農工大学大学院技術経営研究科( $184-8588$ 小 金井市中町 2-24-16)

*2 東京都立大学大学院工学研究科( $192-0397$ 八王子市南大 沢 1-1).

*3 首都大学東京大学院工学研究科( 192-0397 八王子市南大 沢 1-1).

E-mail : motlz019@cc.tuat.ac.jp
小さくなると見掛けの粘度が増加することも明らかに されている。

一方, 近年 Muller-Mohnssen ら (3) により高分子水 溶液の矩形管内速度分布の測定が実験的になされ, 流 れ場の変化が明らかにされている，しかしながら，見 掛けの滑り現象のおもな原因と考えられている管路内 の濃度分布の不均一性に対する実験的な解釈はいまだ 見いだされておらず，これらの現象は高分子の網目構 造や壁面への吸着, shear thinning といったさまざま な問題が絡み合い複雑化していると考えられる。そこ で,これらの問題をより簡略化するためには shear thinning の影響のないような高分子濃度での研究が 必要と考えられる.

よって, 本研究は非ニュートン粘性の無視できる希 薄な高分子水溶液を用いて微小管路内層流の圧力損失 測定および速度分布測定を行い, その流動特性を明ら かにすることを目的とする。

\section{2. 実験装置および方法}

供試流体はニュートン流体として蒸留水を用い, 希 薄高分子水溶液として $0.5 \sim 5 \mathrm{ppm}$ のポリエチレンオ キサイド (商品名 Peo-15) および 1 3 ppmのポリア クリルアミド (商品名 Separan-AP 30) 水溶液を用い 
Table 1 Dimension of micro tubes

\begin{tabular}{|c|c|c|c|}
\hline $\mathrm{d}(\mu \mathrm{m})$ & $1(\mathrm{~mm})$ & $1 / \mathrm{d}$ & \\
\hline 251.8 & 85.0 & 337.6 & \\
\hline 148.4 & 50.0 & 336.9 & \\
\hline 101.8 & 35.0 & 343.7 & \\
\hline 77.7 & 26.0 & 334.4 & \multirow{2}{*}{$\begin{array}{c}\text { Photograph of micro } \\
\text { tube } \\
(\mathrm{d}=50.2 \mu \mathrm{m})\end{array}$} \\
\hline 50.2 & 25.0 & 498.0 & \\
\hline
\end{tabular}

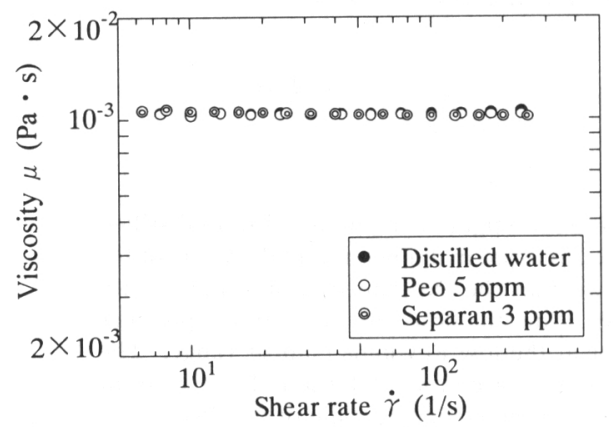

Fig. 1 Viscosity of dilute polymer solutions

た. 図 1 に円すい-平板粘度計 (Anton Paar 社製)を 用いて測定した供試流体の粘度を示す。威 1 より希薄 高分子水溶液として用いた Peo 5 ppm 水溶液および Separan $3 \mathrm{ppm}$ 水溶液が非二ュートン粘性特性をも たないことがわかった. そして, それらは蒸留水の粘 度と土 $1.5 \%$ 以内で一致した. よって, 希薄高分子水 溶液の実験結果の整理には水の粘度を用いた。

供試管はフューズドシリカ製微小円管を用い, 詳細 を表 1 に示す. 管径の測定には光学顕微鏡 (KEYEN$\mathrm{CE}$ 社製) を用いた. 表 1 中の微小円管断面図より, 真 円度が高く表面が滑らかなことがわかる。

測定には図 2 に示す任意の一定流量を長時間供給可 能なピストンとシリンダを備えた定流量吐出し実験装 置を用いた。供試実験装置はコンピュータによりモー 夕回転速度を制御し, ギヤを介してピストンを押し出 し, 流体を流動させるシステムである。

本装置により正しく流量が得られていることを示す ため, 重量法により求めた流量 $Q$ とモー夕回転数に より求めた流量 $Q_{m}$ を比較した結果を図 3 に示す。こ こで流量誤差を次式で定義した.

$$
\varepsilon_{\text {error }}=\frac{Q-Q_{m}}{Q_{m}} \times 100[\%]
$$

図 3 より, 流量誤差は土0.5\%以内であることがわ かり, 本装置により流量が正しく得られていることが

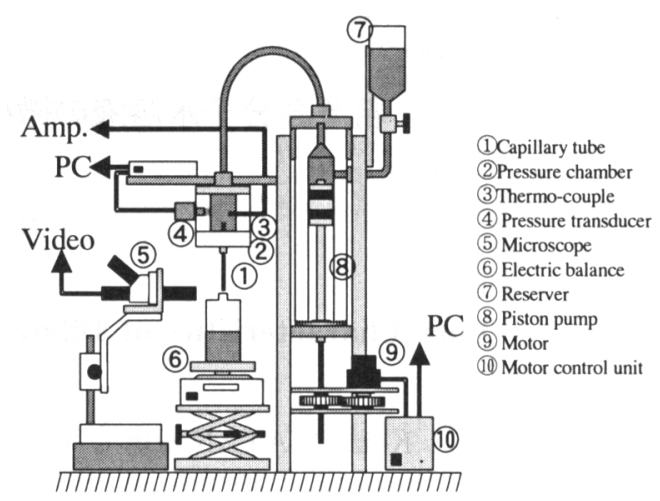

Fig. 2 Pressure drop measurement system

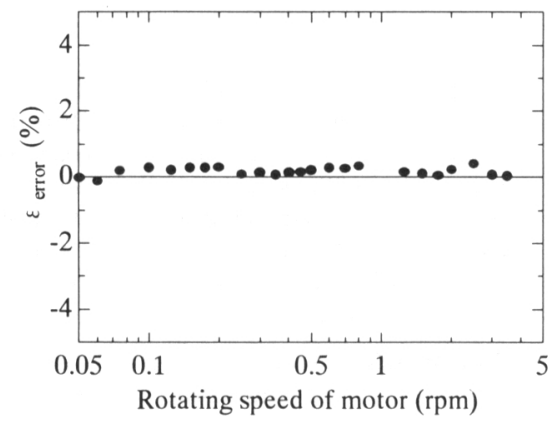

Fig. 3 Error of flow rate

示された.

圧力計はひずみゲージ式圧力変換器で, 許容圧力最 大 $1.0 \mathrm{MPa}$ のものを使用している. 圧力測定は圧力 容器内の圧力を測定しており以下の補正を行った。

$$
\Delta P_{f}=\Delta P-\Delta P_{e}-\Delta P_{o}
$$

ここで, $\Delta P_{f}$ は粘性摩擦損失, $\Delta P$ は測定圧力, $\Delta P_{e}$ は管入口助走区間での損失, $\Delta P_{o}$ は出口における運動 エネルギーの損失である。

また, $\Delta P_{e}$ と $\Delta P_{o}$ の和は一般によく用いられる Hagen-Poiseuille 流れ理論および過去の文献 (4)か ら流体の単位体積あたりの運動エネルギーの 2.2 倍と した. それは以下の式で表される。

$$
\Delta P_{e}+\Delta P_{o}=2.2 \times \frac{\rho v^{2}}{2}=2.2 \times \frac{8 \rho Q^{2}}{\pi^{2} d^{4}}
$$

結果の整理には以下の二つの式を用いた。

$$
\lambda=\frac{\pi^{2} \Delta P_{f} d^{5}}{8 \rho l Q^{2}}
$$

Hagen-Poiseuille 式

$$
Q_{p}=\frac{\pi(d / 2)^{4} \Delta P_{f}}{8 \mu l}
$$

ここで $\rho$ は密度, $d$ は管内径, $\lambda$ は管摩擦係数, $l$ は管 
長, $Q_{p}$ は Poiseuille 流量である.

温度は約 $20^{\circ} \mathrm{C} て ゙$ 行った. 微小な流れ場では温度の 与える粘性への影響が顕著なため, 熱電対を用いて圧 力チャンバ内の管入口温度を $0.1^{\circ} \mathrm{C}$ 単位で測定した. 測定を行った $R e$ 数範囲は $10 〜 500$ である.

\section{3. 実験結果および考察}

図 4 に圧力損失測定により得られた管径 $d=251.8$ $\mu \mathrm{m}$ における管摩擦係数 $\lambda$ の実験結果を示す。実験結 果の精度を調べるため管摩擦係数 $\lambda$ に関して不確か さ解析を行った結果, 直径 $d=251.8 \mu \mathrm{m}$, 管長 $l=85$ $\mathrm{mm}, R e=7.5$ で最も不確かさが大きく, 不確かさ $1.77 \%(99 \%$ 包括度 $)$ であった. 希薄高分子水溶液の管 摩擦係数は濃度の高い供試流体において顕著な差が見 られたため, Peo 5 ppm とSeparan 3 ppm について 結果を示した。直線は二ュートン流体の解析結果であ る $\lambda=64 / R e$ を表す. 図 4 から, 蒸留水の測定值は Hagen-Poiseuille 式とよく一致することがわかる. 一方, Peo 5 ppm 水溶液および Separan 3 ppm 水溶 液が低レイノルズ数範囲で管摩擦係数が $\lambda=64 / R e よ$ り低い值となっていることから流量増加していること がわかる.この流量増加は管径の影響を受ける.

これらの傾向をより明らかにするため図 5,6 にそ れぞれ蒸留水, Peo $5 \mathrm{ppm}$ 水溶液, Separan $3 \mathrm{ppm}$ 水 溶液の流量増加率 $\varepsilon$ を示す。また, 図 7 に管径が実験 結果に及ほす影響を $R e=100$ の場合に対して示す. ここで, 流量増加率 $\varepsilon$ は流出流量 $Q$ と Poiseuille 流



Fig. 4 Friction factor for micro tube $(d=251.8 \mu \mathrm{m})$
量 $Q_{p}$ を用いて以下の式で定義される。

$$
\varepsilon=\frac{Q-Q_{p}}{Q_{p}} \times 100[\%]
$$

図 5 から, 蒸留水の流量増加率は $50.2 \sim 251.8 \mu \mathrm{m}$ の微小管において $2 \%$ となり, ハーゲン・ポアズイ ユの式とよい一致を示した.

一方, 図 6, 7 加, 希薄高分子水溶液の流量増加率 は Re 数の増加および管径の減少とともに減少してい ることがわかる。

Peo 5 ppm 水溶液は $R e<50$ で $50.2 \sim 251.8 \mu \mathrm{m}$ の

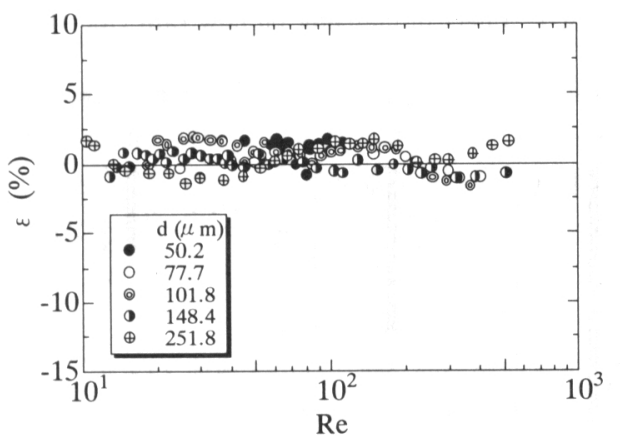

Fig. 5 Flow rate for distilled water

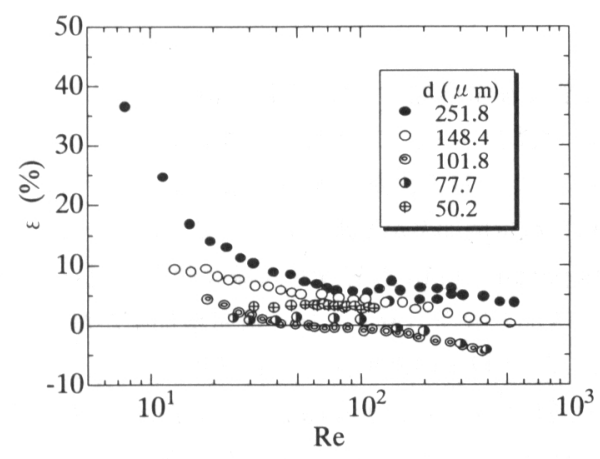

(a) Flow rate for Peo 5 ppm solution

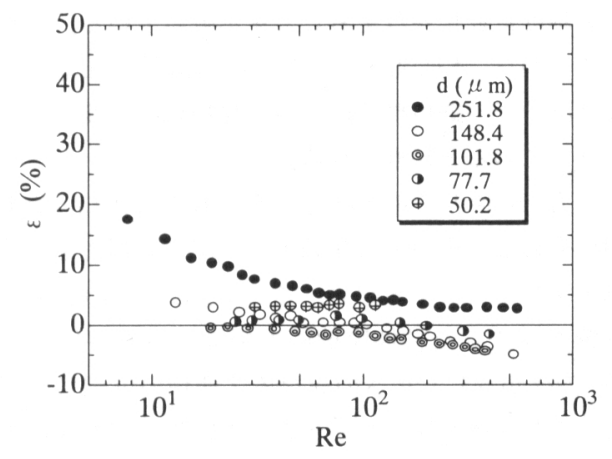

(b) Flow rate for Separan $3 \mathrm{ppm}$ solution

Fig. 6 


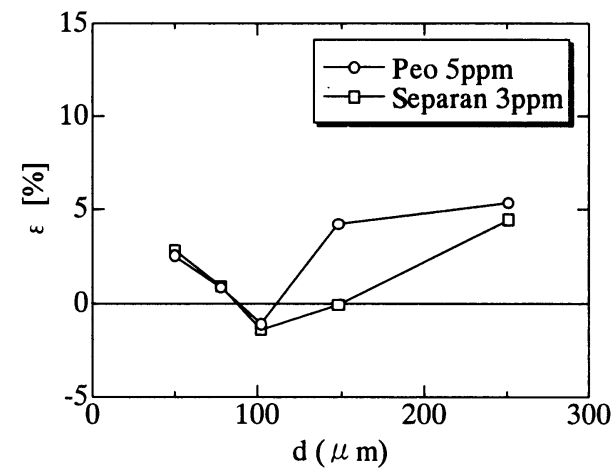

Fig. 7 Effect of diameter on flow rate $(R e=100)$

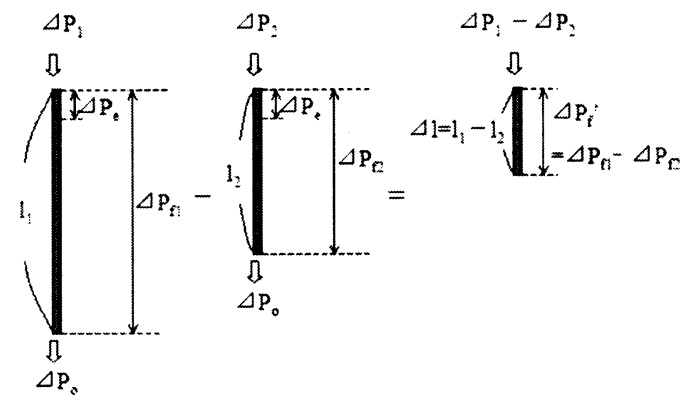

Fig. 8 Concept of the method

微小管で流量増加を示し, 管径の減少とともに流量増 加率が減少する。この流量増加率は管径 $d=101.8$ $\mu \mathrm{m}$ において最も流量増加率が低くなり, $d=77.7 \mu \mathrm{m}$ で再び流量増加率が増加を始めることがわかる.

Separan $3 \mathrm{ppm}$ 水溶液も同様な傾向が見られ, Re 数の増加と管径の減少に伴い流量増加率が減少し, $d$ $=77.7 \mu \mathrm{m}$ 以下の微小管で流量が再び増加を示した。

前述したように, Quibrahim ${ }^{(2)}$ は見掛けの粘度が管 径に依存することを指摘している. 彼は高分子濃度が 高分子網目構造の長さスケールに影響を及ほし，見掛 けの粘度に変化を与えることを示唆している。これら のことから, 本研究における管径の流量増加率への依 存は高分子の網目構造の変化が見掛けの粘度に影響を 及ぼしていると類推される。

一方, 現時点で希薄高分子水溶液の管入口, 助走区 間損失および出口での運動エネルギーの損失を正確に 算定することはできない. そこで,これらの諸損失の 影響を除去した粘性摩擦圧力損失のみを評価するた め, 内径が等しく長さの異なる 2 種類の供試管に等流 量で供試流体を流したときの圧力損失の差を比較する ことにする。

比較に用いた管の詳細を表 2 に示す。管径 251.8
Table 2 Difference of tube length

\begin{tabular}{|c|c|c|c|c|}
\hline \multirow{2}{*}{$\mathrm{d}(\mu \mathrm{m})$} & \multicolumn{3}{|c|}{$\mathrm{l}(\mathrm{mm})$} & \multirow{2}{*}{$\Delta \mathrm{l} / \mathrm{d}$} \\
\cline { 2 - 4 } & $\mathrm{l}_{1}$ & $\mathrm{l}_{2}$ & $\Delta \mathrm{l}\left(\mathrm{l}_{1}-\mathrm{l}_{2}\right)$ & \\
\hline 251.8 & 85 & 60 & 25 & 99.3 \\
\hline 148.4 & 50 & 35 & 15 & 101.1 \\
\hline
\end{tabular}

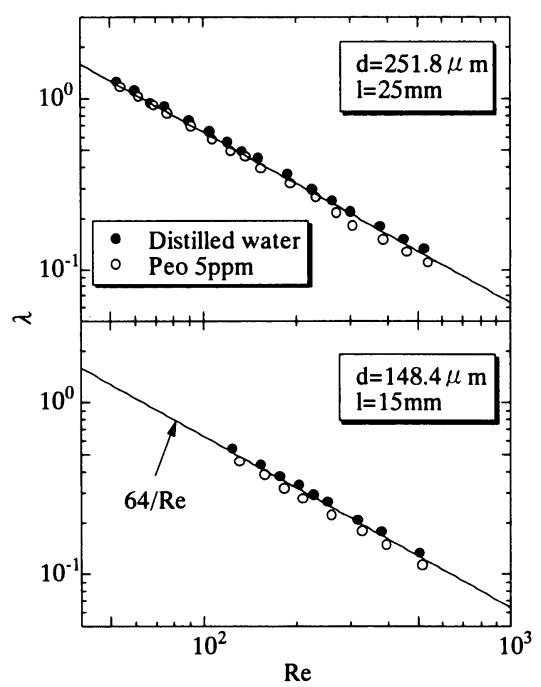

Fig. 9 Friction factor

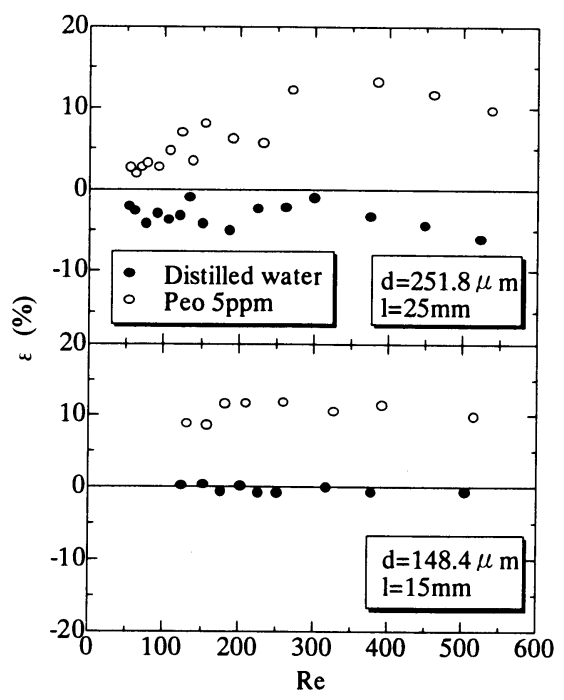

Fig. 10 Flow rate for Peo 5 ppm solution

$\mu \mathrm{m}$ と $148.4 \mu \mathrm{m}$ の長さの異なる管を用い, $1 / d$ は約 100 とした.

実験結果の整理は図 8 に示す方法で行った。長さの 異なる 2 種類の微小円管の圧力損失 $\Delta P_{1}$ および $\Delta P_{2}$ を測定した。ここで, 圧力損失は式 (2)に示すとおり 




Fig. 11 Micro PIV system

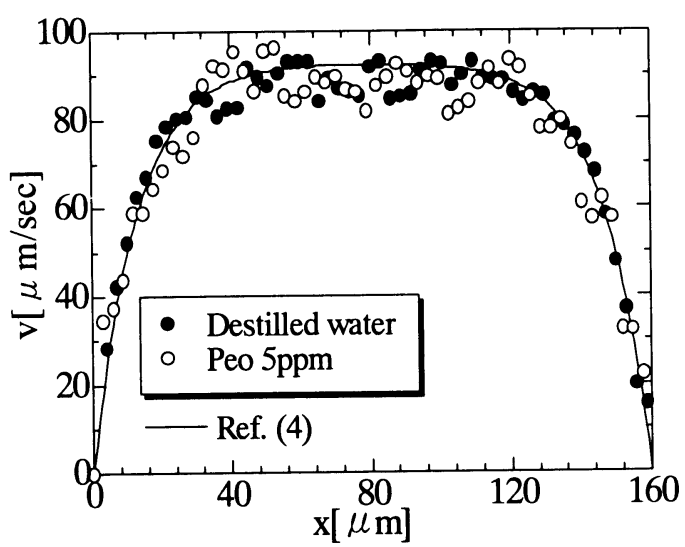

Fig. 12 Velocity profile $\left(R e=6.6 \times 10^{-3}\right)$

粘性摩擦損失圧力および管入口助走区間の損失 $\Delta P_{e}$, 出口での運動エネルギーの損失 $\Delta P_{0}$ からなるが, 等流 量で流動していることから入口出口の損失は等しいと みなせる.よって, 長さの異なる 2 種類の微小管の圧 力損失の差から見掛けの管長 $\Delta l$ の微小管の粘性摩擦 損失圧力が求まる。

実験結果を図 9 に示す. 図 9 から Peo $5 \mathrm{ppm}$ 水溶 液の管摩擦係数が $\lambda=6 \dot{4} / \mathrm{Re}$ より低い值となっている ことがわかる.結果をより明確に示すため, 図 10 に 流量增加率で整理した. 図 10 より蒸留水の流量增加 率が士5\%以内であるのに対し, Peo $5 \mathrm{ppm}$ 水溶液は 最大約 $15 \%$ の流量増加を示していることがわかる. このことから, 蒸留水の結果と比較して, Peo $5 \mathrm{ppm}$ 水溶液が粘性摩擦損失の低下により流量増加を示すこ とが明らかとなった。また，これらの流量増加率が図 6 で得られた値よりも大きいことから，高分子の添加 により管入口出口損失が水よりも低隇していると考え られる。

上述の流量増加のメカニズムを明らかにするため, マイクロ PIVによる矩形微小管路内の速度分布測定 を行った。速度分布測定には図11に示すマイクロ
PIV システムを用いた，供試管としてシリコンと Pyrex ガラスからなる幅 $w=160 \mu \mathrm{m}$, 高さ $h=43 \mu \mathrm{m}$ の矩形微小管を使用し，供試流体は蒸留水および Peo $5 \mathrm{ppm}$ 水溶液を用いた。供試流体には直径 $1 \mu \mathrm{m}$ の蛍 光粒子を混入しレーザ励起により可視化を行った. 流 体はシリンジポンプにより一定流量で押し出され, 微 小管を通り流出する. 得られた可視化映像を ICCD カ メラを用いて $1 / 30$ 秒間隔で 130 枚撮影し，画像群と してコンピュータに取り込む. 保存された画像群を画 像処理ソフト Dipp-Flow により低密度 PIV 解析を行 い平均ベクトルを得た。測定を行った $R e$ 数は $6.6 \times$ $10^{-3}$ である. 本レイノルズ数は圧力損失実験と比較 して非常に小さいが, 流れは層流であるので本質的な 流動状態に違いはないと考えられる。ささらに, 流路幅 が $160 \mu \mathrm{m}$ と圧力測定で流量増加が見られた管径とほ ほ同じであるため, 本速度分布測定で得られた結果か ら, 流量增加のメカニズムを考察できると考えられ る.

マイクロ PIV 装置を用いて得られた矩形管路内速 度分布の測定結果を図 12 に示す. 図 12 中の実線は供 試矩形管のニュートン流体に対する厳密解 ${ }^{(5)}$ で以下 に示す.

$$
\begin{aligned}
v & =\frac{y}{2 \mu}\left(-\frac{d p}{d z}\right)(h-y)-\frac{4 h^{2}}{\pi^{3} \mu}\left(-\frac{d p}{d z}\right) \\
& \times \sum_{n=1,3, \ldots}^{\infty} \frac{1}{n^{3}} \sin \left(\frac{n \pi}{h} y\right) \frac{\cosh \{(n \pi / h)(x-w / 2)\}}{\cosh (n \pi w / 2 h)}
\end{aligned}
$$

ここで, $h$ は矩形管高さ, $w$ は矩形管の幅である. 図 12 は管中央 $(z=21.5 \mu \mathrm{m})$ の測定結果で, 横軸 $x$ は 矩形管の幅 $w$ で $x=0,160 \mu \mathrm{m}$ は壁面の位置を示して いる. 蒸留水の結果は矩形管路内速度分布の厳密解と よい一致をしている。一方, Peo $5 \mathrm{ppm}$ 水溶液におい て蒸留水との差はほとんど認められず, Muller-Mohnssen ら (3)により示された $0.25 \mathrm{wt} \%$ 陰イオンポリア クリルアミド水溶液の速度分布のような顕著な変化は 見られなかった。本研究で測定された速度分布の分解 能は壁面から $3 \mu \mathrm{m}$ である. 従来の研究(1)のポリマの 壁面への吸着厚さは $0.8 \sim 1.5 \mu \mathrm{m}$ であるという報告 から考えると, 本研究においても $3 \mu \mathrm{m}$ 以下の壁面近 傍領域で流れが変化していることが考えられる.

\section{4. 結 論}

非ニュートン粘性の無視できる希薄な高分子水溶液 の微小円管内流動特性を明らかにすることを目的と し, 直径が 50〜250 $\mu \mathrm{m}$ の微小管に対する圧力損失測 定および速度分布測定を行った. 本研究の結論は以下 
のようにまとめられる。

（1）同一管径で管長の異なる 2 種類の管を用いて 粘性摩擦損失圧力を測定し, それらの測定值の比較か ら, Peo $5 \mathrm{ppm}$ 水溶液が直径 $148.4 \mu \mathrm{m}$ と $251.8 \mu \mathrm{m}$ の管で最大約 $15 \%$ の流量増加を生じることを明らか にした.

（2）マイクロ PIV 測定により, Peo $5 \mathrm{ppm}$ 水溶 液の速度分布に蒸留水の結果と顕著な差異が認められ なかった.このことから, 圧力損失測定で得られた流 量増加は壁面近傍の流れの特異性によるものと考えら れる.

終わりに, マイクロ PIV 測定について協力いただ いた本学マイクロプロセス工学講座の楊明助教授およ び博士課程 3 年の神田健介氏に感謝する. また, 本研
究の一部は平成 16 年度科学研究費萌芽研究 (No. 16656066)の援助を受けたことを記し謝意を表す。

\section{文献}

(1) Cohen, Y. and Metzner, A. B., Apparent Slip Flow of Pelymer Solutions, J. Rheol., 29 (1985), 67-102.

(2) Quibrahim, A., Excess Pressure Drop of Polymer Solutions in Laminar Capillary Tube Flows, Phys. Fluids, 22 (1979), 784-785.

(3) Muller-Mohnssen, H., ほか 2 名, Direct Determination of Apparent Slip for a Ductec Flow of Polyacrylamide Solutions, J. Rheol., 31 (1987), 323-336.

(4) Schmidt, F. and Zeldin, B., Laminar Flows in Inlet Sections of Tubes and Ducts, AIChE J., 15-4 (1969), 612-614.

( 5 ) Comish, R. J., Proc. R. Soc., London, Ser. A, 120 (1928), 691. 